\title{
PERVIVENCIAS DEL CUENTO MEDIEVAL EN LA TRADICIÓN SEFARDÍ CONTEMPORÁNEA
}

\author{
María SÁnChEz-PÉRez \\ Universidad de Salamanca \\ mariasanchezperez@usal.es
}

\section{Introducción}

Cualquier persona que pretenda conocerse, o mejor, reconocerse como miembro de una familia, una comunidad o una sociedad afirmará que, en muchas ocasiones, son los bienes intangibles los que le permiten identificarse como tal. Será, en buena medida, el patrimonio inmaterial lo que le vincule y le convierta en integrante de esa cultura. Con ello no nos referimos únicamente a las tradiciones, a los usos sociales y rituales, que pueden variar - por muchos y diversos motivos- a lo largo de los siglos, sino más bien a los recuerdos, a los momentos compartidos -festivos o graves-, a las experiencias vividas, etc., como individuos, pero también como piezas de un colectivo. En este sentido, la cultura o, para el caso que nos ocupa, la literatura popular, de tradición fundamentalmente oral, ha jugado desde siempre un papel de relevancia excepcional en el reconocimiento de todos nosotros como parte integrante de una sociedad. Por eso, por mucho que las formas de comunicación hayan cambiado en los últimos tiempos -no ya solo con las nuevas tecnologías-, cuando pensamos quiénes somos y de dónde venimos podremos reconocernos en una serie de recuerdos que nos unen a nuestros mayores, a nuestro pasado y a nuestro entorno, vinculados a la transmisión de saberes y valores, de generación en generación, gracias a la palabra hablada -fundamentalmente, pero también escrita-. Los refranes, cuentos, leyendas, acertijos, canciones, etc., que todos -o muchos- hemos escuchado desde nuestra infancia nos permiten (re)conocernos a nosotros mismos y a los que nos rodean. Sin embargo, frente a los abundantes estudios que hoy existen en torno a las grandes obras y figuras -de diversas artes-, las diferentes parcelas 
que conforman el folclore cultural y literario de una cultura o una sociedad siguen estando bastante desatendidas, a pesar, como decimos, de que son las que nos hacen reconocernos, en más de una ocasión, como miembros de una colectividad e integrantes de un pueblo.

Desde siempre se han contado historias y relatos, fábulas, exempla, etc., y durante siglos se transmitieron de forma oral y no siempre se consignaron por escrito. De ahí que esta «otra» literatura se viese desatendida y marginada durante centurias ${ }^{1}$. Una obra literaria puede llegar a ser «marginal» por diversos motivos, entre ellos: por su forma de transmisión -como puede ser el caso de la literatura oral o popular-, pero también por haberse producido en lenguas que no son de las culturas dominantes, es decir, en lenguas minoritarias. Ambas características las comparte, en la actualidad, el cuento folclórico sefardí. Sin embargo, como veremos, algunos de esos apólogos, cuentos o facecias parecen remontarse a la Edad Media, al período de tiempo en el que se produjo la convivencia en la Península de cristianos, musulmanes y judíos, y en aquel momento sí fueron, muchos de esos textos, recogidos por escrito y, por lo tanto, pasaron a pertenecer a la literatura culta o canónica. Eso no impide, por otro lado, que, aun consignados por escrito, no fuesen escuchados durante siglos gracias a las lecturas en voz alta.

\section{El cuento medieval y la konseja sefardí}

Refiriéndonos a la realidad hispánica de la Edad Media, sabemos que las colecciones de exempla empezaron a proliferar primero en latín y después en romance. El pionero fue el judío converso Pedro Alfonso con su Disciplina clericalis, que resulta ser:

un testimonio perfecto de la encrucijada cultural en la que nace. Sus fuentes van desde Esopo (V), y las famosas colecciones orientales, Barlaam (XXII), Calila (XXIV) y Sendebar (XI, XIII), a la tradición folclórica hebrea (XVII), junto con proverbios de ascendencia bíblica. Todo ello es un indicio del patrimonio narrativo de un hebreo culto en la España del XII, es decir, antes de que las colecciones citadas fueran traducidas al castellano ${ }^{2}$.

${ }^{1}$ Véase el estudio clásico de M. ${ }^{a}$ Cruz García de Enterría, Literaturas marginadas, Madrid, Playor, 1983.

${ }^{2}$ María Jesús Lacarra, Cuentos de la Edad Media, Madrid, Castalia, 1998, p. 12. Desde entonces y, a partir fundamentalmente del siglo XIII, las colecciones de exempla en castellano comienzan a desarrollarse, integrando casi siempre textos de proveniencia oriental. Véase: María Jesús Lacarra y Juan Paredes, eds., El cuento oriental en Occidente, Granada, Comares, 2006. 
A partir de entonces, pero, sobre todo, gracias al despertar cultural del siglo XIII, estas colecciones se incrementarán con obras como Sendebar o Calila e Dimna, al traducirse al castellano. De este modo, tal y como afirmaba Maxime Chevalier, los relatos breves se orientarán en tres direcciones: a) la fábula; b) el chiste o relato jocoso; c) el exemplum ${ }^{3}$. Más tarde, autores como Juan Ruiz o don Juan Manuel, entre otros, aprovecharán muchos de esos materiales procedentes de tradición oriental, pero también clásica y eclesiástica. Respecto a la primera, tuvo una relevancia fundamental en el desarrollo de la cuentística medieval gracias a la convivencia -como señalábamos- de cristianos, musulmanes y judíos en la Península.

Con posterioridad, concretamente el 31 de marzo de 1492, Fernando e Isabel firmaron en Granada el decreto por el que se les daba a los judíos el plazo de cuatro meses para abandonar la Península. A partir de ese momento se produjo la diáspora y unos cien mil judíos se fueron asentando en diferentes países: Portugal, Italia, los Países Bajos, el norte de África, etc., pero, fundamentalmente, el Oriente mediterráneo. Los descendientes de estos judíos, conocidos como sefardíes, se caracterizaron desde entonces hasta nuestros días por dos rasgos principales: su religión -el judaísmo-y sus orígenes hispánicos ${ }^{4}$. En su bagaje cultural llevaron todo aquello que habían asimilado en su convivencia con musulmanes y cristianos y, cómo no, exempla, relatos breves, cuentos, romances, refranes, etc. Por lo tanto, en muchas ocasiones, la base de estos apólogos será fundamentalmente hispánica ${ }^{5}$.

Mientras que el cuento medieval ha sido bastante atendido por la crítica y existen diversos estudios sobre él, de las narraciones populares sefardíes contamos fundamentalmente con antologías, pero no tanto con investigaciones específicas centradas en esos cuentos ${ }^{6}$. Entre los conocidos como géneros tradi-

\footnotetext{
${ }^{3}$ Véase su introducción (fundamentalmente pp. 9-10) a la edición de María Jesús Lacarra, Cuento y novela corta en España. 1. Edad Media, Barcelona, Crítica, 1999. Cierto es, por otro lado, que en aquellos momentos comienza a proliferar la literatura sapiencial de sentencias, la literatura gnómica, junto con estos cuentos, pero también catecismos, etc. Obras como: Bocados de oro, Historia de la doncella Teodor o el Sendebar pueden ser considerados géneros distintos y, por lo tanto, normalmente se han estudiado en apartados diferentes y, sin embargo, «comparten muchos rasgos en común, desde su remoto origen oriental, directo en unos casos o indirecto en otros, hasta su contenido sapiencial», en María Jesús Lacarra y Juan Manuel Cacho Blecua, Historia de la literatura española. 1. Entre oralidad y escritura, Barcelona, Crítica, 2012, p. 393.

${ }^{4}$ El término sefardí proviene de un topónimo hebreo con el que los judíos denominaban a la península Ibérica, Sefarad, que para ellos significaba el extremo más occidental del mundo conocido.

${ }^{5}$ En la actualidad, los sefardíes no solo conocen muchas narraciones por su pasado hispánico, sino que un buen número las han asimilado también por su convivencia con otras culturas y otras comunidades, y, a veces, es difícil saber por qué vía y medio les llegó.

${ }^{6}$ Sobre el cuento medieval véanse como estudios de conjunto, además de los arriba citados: María Jesús Lacarra, Cuentística medieval en España: los orígenes, Zaragoza, Universidad de Zaragoza, 1979; María del Carmen Hernández Valcárcel, El cuento medieval español: revisión crítica y antología, Murcia,
} 
cionales de la literatura sefardí se encuentran los cuentos populares -junto con el refranero, el romancero y el cancionero- ${ }^{7}$. Normalmente el nombre que se les da en judeoespañol es konseja o konsejika para referirse a estas narraciones tradicionales ${ }^{8}$. Estos relatos no solo han servido para entretener a los niños, sino que, desde siempre, han jugado un importante papel en la vida de los adultos. Cuenta Michael Molho que era habitual contarlos durante las largas veladas:

Después o antes de la cena, los vecinos se reunían y se divertían en común, al no existir por entonces [en la época del imperio turco] periódicos, revistas ilustradas y otras distracciones... Si las noches de invierno eran muy largas, ¿cómo matar el tiempo? El único entretenimiento que quedaba era la narración de cuentos y consejas?.

Desde siempre, por tanto, en las comunidades sefardíes ha tenido gran importancia la narración de cuentos y relatos -así como también, por ejemplo, la transmisión de canciones y refranes-, como parte de su tradición y su cultura ${ }^{10}$.

Universidad de Murcia, 1997; Jesús Maire Bobes, ed., Judíos, moros y cristianos: cuentos españoles del siglo XII al XVII, Madrid, Akal, 2008. Sobre los cuentos populares sefardíes del imperio otomano existen varias antologías de Matilda Koen-Sarano: Kuentos del folklor de la famiya djudeo-espanyola, Jerusalén, Kana, 1986; Djoha ke dize? Kuentos populares djudeo-espanyoles, Jerusalén, Kana, 1991; Konsejas i konsejikas del mundo djudeo-espanyol, Jerusalén, Kana, 1994; De Saragosa a Yerushaláyim. Kuentos sefaradís, Zaragoza, IberCaja, 1995; Lejendas i kuentos morales de la tradisión djudeo-espanyola, Jerusalén, Kana, 1999; Kuentos salados djudeo-espanyoles, Valencia, Edisiones Capitelum, 2000. Véase también Dan Ben-Amos et al., Folktales of the Jews. Volume 1. Tales from the Sephardic Dispersion, Filadelfia, The Jewish Publication, 2006. Una antología del cuento folclórico sefardí del norte de Marruecos en Arcadio de Larrea Palacín, Cuentos populares sefardies de los judios del norte de Marruecos, Tetuán, Instituto General Franco, 1952-1953, 2 vols. Un estudio junto con una antología del cuento folclórico sefardí en Tamar Alexander-Frizer, The Heart is a Mirror. The Sephardic Folktale, Detroit, Wayne State University Press, 2008. Y como catálogo fundamental del cuento folclórico sefardí véase Reginetta Haboucha, Types and Motifs of the Judeo-Spanish Folktales, Nueva York y Londres, Garland, 1992. Dejamos fuera de este trabajo los cuentos que aparecen insertos en la literatura rabínica o aquellos que fueron traducidos del hebreo. Por lo tanto, nos centraremos únicamente en los cuentos folclóricos sefardíes, de carácter popular y que se transmitieron de forma fundamentalmente oral durante generaciones.

${ }^{7}$ Dicha denominación se contrapone a los géneros adoptados con los que se denomina a aquellos que carecían de tradición en la literatura sefardí y que comenzaron a cultivarse a partir de mediados del siglo XIX en un afán por imitar a las literaturas occidentales. Dentro de estos géneros adoptados se engloba el teatro, la poesía de autor, la narrativa y el periodismo.

${ }^{8}$ «Algunos sefardíes hacen una sutil distinción entre la conseja, que sería una narración de carácter fantástico, muchas veces con elementos mágicos y maravillosos y la consejica, que sería el cuento humorístico breve», en Paloma Díaz-Mas, Los sefardies. Historia, lengua y cultura, Barcelona, Riopiedras, 2006, p. 172.

${ }^{9}$ Apud. ibidem. Incluso Díaz-Mas señala -aportando testimonios- cómo era también frecuente la narración de estos cuentos durante el día de descanso en el judaísmo, el shabat, pero también en los duelos y las visitas de pésame.

${ }^{10}$ No en vano lo mismo ha pasado en España: tanto la narración de historias como las lecturas en voz alta se produjeron desde la alta Edad Media hasta épocas recientes, por no decir hasta la actualidad. Clásico, aunque fundamentalmente destinado a los Siglos de Oro, es el estudio de Margit Frenk, Entre 
Respecto a los temas, lógicamente son muy variados. Los más típicamente sefardíes serían los que tienen como protagonistas a rabinos o personajes de la Biblia -el rey Salomón, el profeta Elías, etc.-, y los protagonizados por Djohá -al que nos referiremos más adelante-. Es cierto, además, que no son muy abundantes las fábulas ni los cuentos de animales ${ }^{11}$. En resumen:

Los temas de estos cuentos [...] son antiguos y universales y nos indican que parte de los cuentos pueden muy bien venir de los tiempos en que los judíos estaban todavía en España. Por medio de estos cuentos pasaron desde una generación a la otra valores, figuras históricas, sucesos, maneras de pensar, usos y costumbres, vestimentas y comidas. Así que por medio del cuento popular judeo-español es posible hacer la construcción, algunas veces real y otras idealizada, de un mundo rico de historia, de tradición judía y no judía $[\ldots]^{12}$.

Así pues, durante siglos, esta literatura oral y, fundamentalmente, popular no se consignó por escrito, pero sí fue un fenómeno muy vivo en la tradición judeoespañola. Nuestro interés ahora es mostrar cómo diferentes cuentos de la Edad Media han pervivido en la tradición sefardí muchos años después de su expulsión en 1492.

\section{Estudios precedentes}

Algunas investigaciones anteriores han mostrado semejanzas y paralelismos entre ciertos apólogos castellanos y sefardíes, desde diferentes puntos de vista. Una de las pioneras en este campo fue la romanista Cynthia M. Crews, quien en las primeras décadas del siglo $\mathrm{xx}$-especialmente en los años 30 - se dedicó a recoger cuentos vivos en la tradición oral, en sus viajes por los Balcanes. Aunque a ella le interesaron, fundamentalmente, por su valor lingüístico, bien es cierto que hoy en día siguen interesando también por su interés literario ${ }^{13}$.

la voz y el silencio. La lectura en tiempos de Cervantes, Alcalá de Henares, Centro de Estudios Cervantinos, 1997.

${ }^{11}$ Un estudio de una fábula publicada en un periódico sefardí puede verse en María Sánchez-Pérez, «Tradición y modernidad: La fábula La rapoza se va al hadjilik en el periódico sefardí El Konsejero (Salónica, 1913)», en Estudios Humanísticos. Filología, 35 (2013), pp. 109-120. Actualmente, seguimos con el análisis y estudio de algunas fábulas publicadas en periódicos sefardíes entre finales del siglo XIX $\mathrm{y}$ principios del $\mathrm{xx}$.

${ }^{12}$ Matilda Koen-Sarano, De Saragosa..., p. 20.

${ }^{13}$ Entre los estudios de Cynthia M. Crews destacamos: «Judaeo-Spanish Folktales in Macedonia», en Folk-lore, 43 (1932), pp. 193-225; Recherches sur le Judéo-Espagnol dans les Pays Balkaniques, París, Droz, 1935; «The Friend and a Half», en The Slavonic (and East European) Review XVI.47 (en 1938), pp. 312-319; «A Salonica Conseja», en Le Judaïsme Sephardi, 6 (marzo 1955), pp. 278-279; 
Hay que destacar también la labor de los hispanistas Samuel G. Armistead y Joseph H. Silverman. Sus investigaciones se centraron, en un primer momento, especialmente en el romancero hispánico, de ahí que se interesaran pronto por la tradición sefardí. Sin embargo, sus encuestas de campo les llevaron no sólo a recoger muestras de ese patrimonio, sino que atendieron a otros muchos aspectos de la literatura de transmisión oral, como las adivinanzas o el cancionero, pero también los cuentos populares ${ }^{14}$.

Años después, en 1999, Julio Camarena publicaba un breve, pero sugerente trabajo en el que analizaba, fundamentalmente: la escasez de cuentos sobre animales en el repertorio sefardí -frente a otras culturas, como la hispáni$\mathrm{ca}^{15}$-, cómo un antiguo refrán español se recrea y da forma a un cuento en judeoespañol, y la importancia del cuento religioso y ejemplarizante. También señalaba que existen concomitancias en cuanto a tramas y mensajes, pero que aún quedaba mucho camino por recorrer ${ }^{16}$.

Como no podía ser de otra manera, uno de los más reputados folcloristas, José Manuel Pedrosa, ha dedicado varios estudios a presentar semejanzas y paralelismos entre diferentes textos -fundamentalmente orales y populares,

«Two Salonica Consejicas», en Le Judaïsme Sephardi, 7 (junio 1955), pp. 294-295; «Reflections on Judaeo-Spanish by a Spanish Jew», en Vox Romanica, 20 (1961), pp. 327-334; «Textos judeo-españoles de Salónica y Sarajevo con comentarios lingüísticos y glosario», en Estudios sefardies, 2 (1979), pp. 91258. Cynthia M. Crews y Anna Angelopoulos (ed. y trad.), Contes judéo-espagnols des Balkans, París, José Corti, 2009. Para más bibliografía sobre Cynthia M. Crews véanse: Leonor Carracedo y Iacob M. Hassán, «Bibliografía de Cynthia Crews», en Estudios sefardies 2 (1979), pp. 277-287, donde se comenta la bibliografía de la romanista por orden cronológico y con breve descripción de los contenidos de cada una de las entradas; y también Sefardiweb del CSIC: http://sefardiweb.com/bibliografiasefardi/ C?field_bib_apeynom_value $=$ crews $\&$ field_bib_anyo_value $=\&$ field_bib_titulo_value $=\&$ field_bib_ resumen_value $=$ [consultada el 3 de febrero de 2015]. Actualmente, existe una edición en curso sobre otros cuentos tradicionales recogidos por Cynthia M. Crews, consúltese: Aitor García Moreno, «Más textos judeoespañoles de Salónica: avance de la edición de diez cuentos sefardíes tradicionales, recogidos por Cynthia M. Crews a principios del siglo xx», en Estudios sefardies dedicados a la memoria de Iacob M. Hassán (z’’l), ed. de Elena Romero, Madrid, CSIC, 2011, pp. 191-203.

${ }^{14}$ Destacamos ahora los siguientes trabajos: Samuel G. Armistead, «Judeo-Spanish Traditional Literature: Half a Century of Fieldwork and Scholarship», en European Judaism, 44.1 (Spring 2011), pp. 98-106. Las investigaciones conjuntas de Samuel G. Armistead y Joseph H. Silverman: «Another Ballad Publication of Yacob Abraham Yoná», en La Corónica, 5.2. (1977), pp. 110-112; «Dos consejas sefardíes», en Narraciones hispanoamericanas de tradición oral: antología, Madrid, E.M.E.S.A., 1972, pp. 95-101; «Sephardic Folkliterature and Eastern Mediterranean Oral Tradition», en Musica Judaica, 6.1 (1983-1984), pp. 38-54. Y también: Samuel G. Armistead, Reginetta Haboucha y Joseph H. Silverman, «Words Worse than Wounds: A Judeo-Spanish Version of a Near Eastern Folktale», en Fabula (Zeitschrift für Erzählforschung), 23 (1982), pp. 95-98. Más datos en la siguiente dirección de Sefardiweb del CSIC: http://sefardiweb.com/bibliografiasefardi?field_bib_apeynom_value=armistead\&field_bib_anyo_ value $=\&$ field_bib_titulo_value $=\&$ field_bib_resumen_value $=$ cuento [consultada el 4 de febrero de 2015].

${ }^{15}$ Parte de los datos que ya había expuesto Paloma Díaz-Mas en Los sefardies..., pp. 171-174.

${ }^{16}$ Julio Camarena, «Cuento español, cuento sefardí: paseo entre dos mundos», en Jewish Studies at the Turn of the 20th Century, ed. de Judith Targarona y Ángel Saez-Badillos, Leiden, Boston y Colonia, Brill, 1999, vol. II, pp. 485-490. 
pero no solo- en numerosas lenguas, culturas y latitudes: romances, canciones, etc. Para el caso que nos ocupa, destaco dos artículos: uno, en el que analiza los «cuentos de reír» de Ya'acob Abraham Yoná17; y otro en el que analiza la figura de Djohá desde la tradición árabe-islámica, la sefardí y, finalmente, la universal ${ }^{18}$.

En 2003, Paloma Díaz-Mas analizó un cuento inserto en la obra de Cervantes La gran sultana y mostró sus precedentes en la literatura europea en latín, en otras lenguas -como el alemán y el italiano-, en fuentes españolas de los Siglos de Oro y también en la tradición popular sefardí y en los países islámicos ${ }^{19}$. En este trabajo se centraba en estudiar: «El cuento del hombre humilde que promete a un poderoso enseñar a hablar (o a leer) a un animal en un plazo determinado $»^{20}$. A pesar de estar presente en la literatura de diferentes latitudes, la autora no pudo averiguar si «Cervantes tomó el cuento de la oralidad o de una fuente literaria»-caso, por ejemplo, del latín, el italiano o de su contacto con el mundo árabe-islámico durante su cautiverio- ni encontró versiones «en las principales colecciones de la tradición oral moderna peninsular ni hispanoamericana» ${ }^{21}$. En el caso del cuento inserto en La gran sultana el animal es un elefante, pero en otros casos se trata de asnos, o por ejemplo, un gato, tal y como lo recoge Matilda Koen-Sarano en la tradición sefardí y que también señala Díaz-Mas ${ }^{22}$.

\footnotetext{
${ }^{17}$ Ya'acob Abraham Yoná (Monastir, 1847-Salónica, 1922) fue un conocido coplero e impresor muy apreciado en Salónica. Compuso numerosas coplas en judeoespañol, compiló varios libros aljamiados donde se contenían refranes, romances y canciones. Imprimió relatos y fue también autor de varias misceláneas. Fue cantor sinagogal y kombidador, cuya tarea «consistía en ir de casa en casa para convidar oralmente a los invitados que participarían en una boda o una circuncisión, ya que en aquella época, al menos entre las clases populares, no se solían repartir invitaciones escritas» en Béatrice Bänziger, «Las 'prosicas de pasatiempo' de Ya'acob Abraham Yoná», en Acta Romanica Basiliensia-ARBA, 14 (2003) (= «Sala de pasatiempo»: textos judeoespañoles de Salónica impresos entre 1896 y 1916, dir. de Beatrice Schmid), pp. 25-68; concretamente la cita está tomada de la p. 26. Para más datos sobre Yoná, véase Samuel G. Armistead y Joseph H. Silverman, The Judeo-Spanish Ballad Chapbooks of Yacob Abraham Yoná, Berkeley, Los Ángeles y Londres, University of California Press, 1971, y Sefardiweb del CSIC: http://sefardiweb.com/node/222 [consultada el 12 de enero de 2015].

${ }^{18}$ José Manuel Pedrosa, «Los Cuentos hermośos de reir de Yoná: tradición sefardí, tradición hispánica, tradición universal» en Acta Romanica Basiliensia-ARBA, 14 (2003) (=»Sala de pasatiempo»: textos judeoespañoles de Salónica impresos entre 1896 y 1916, dir, Beatrice Schmid), pp. 69-84; José Manuel Pedrosa, «Los cuentos de Yohá: tradiciones sefardí, árabe-islámica y universal», en Judeo Espagnol: Social and cultural life in Salonika through judeo-Spanish Texts, ed. de Rena Molho, Salónica, Ets Ahaim Foundation, 2008, pp. 111-119.

${ }^{19}$ Paloma Díaz-Mas, «Cómo enseñar a hablar a un elefante: un cuento de La gran sultana», en Criticón, 87-88-89 (2003), pp. 265-276.

${ }^{20}$ Ibídem, p. 266. Díaz-Mas señala que se trata del motivo folclórico K.551.11 de la obra de Stith Thompson, Motif-Index of Folk Literature, Bloomington, Indiana University, 1955-1958, 6 vols.

${ }^{21}$ Ibidem, p. 271.

${ }^{22}$ Ibidem, p. 272, nota 21.
} 
Unos años más tarde, en 2010, yo misma estudié cómo dos facecias incluidas en un periódico sefardí de 1909 resultaron ser cuentos tradicionales conocidos en distintas culturas y épocas ${ }^{23}$. Especialmente interesante era el primero: publicado como chiste en el periódico sefardí Yerushalayim (Jerusalén, 1909) resultó ser una versión en judeoespañol de un conocido cuento en la tradición hispánica denominado como el Ejemplo del ermitaño bebedor y que lo encontramos en diferentes obras de la literatura medieval castellana, como el Libro de Apolonio, el Libro de buen amor, el Libro de los exemplos por a.b.c. o El espéculo de legos. Verdad es que no pudimos averiguar si el cuentecillo lo conocían los sefardíes a través de la literatura medieval hispánica o si les llegó a través del mundo musulmán en su diáspora por diferentes países islámicos.

Antonio Cid, en un trabajo de 2012, presentaba una transcripción y edición de un fragmento del Sendebar que se conserva entre los documentos de la guenizá de El Cairo. Tras documentar varias versiones y, gracias a un estudio lingüístico, planteaba que probablemente la traducción sefardí no provenga de la Edad Media, sino de los Siglos de $\mathrm{Oro}^{24}$.

Por último, en 2014, Željko Jovanović publicó dos trabajos relacionados con el cuento popular: en uno se analizan, con un enfoque comparatista, diferentes versiones del cuento Las orejas de Midas o Las orejas de asno; el segundo trata sobre un cuento sefardí aparentemente popular publicado en un periódico serbio -El Amigo del Pueblo (Belgrado, 1888)- que resultó ser una adaptación de la novelita Los tres maridos burlados de Tirso de Molina ${ }^{25}$.

Estos serían los estudios que más se han aproximado a intentar localizar diferentes versiones, paralelismos, etc., entre cuentos en las tradiciones hispánica y sefardí. Con todo, como ya señalaba Julio Camarena en 1999, el camino está abierto y queda mucho por explorar. Por eso nuestro propósito en las siguientes páginas es mostrar cómo cuentos que se conocían en la península Ibérica en la Edad Media continúan vivos en la tradición sefardí en la actualidad. Para ello analizaremos tres narraciones ${ }^{26}$.

${ }^{23}$ María Sánchez-Pérez, «Entre escritura y oralidad: cuentos tradicionales en el periódico sefardí Yerushalayim (1909)», en Los sefardies ante los retos del mundo contemporáneo. Identidad y mentalidades, ed. Paloma Díaz-Mas y María Sánchez-Pérez, Madrid, CSIC, 2010, pp. 193-202.

${ }^{24}$ Antonio Cid, «Un Sendebar sefardi»», en Aljamías. In memoriam Álvaro Galmés de Fuentes y Iacob M. Hassán, ed. de Raquel Suárez García e Ignacio Ceballos Viro, Gijón, Trea, 2012, pp. 297-348.

${ }^{25}$ Los artículos de Željko Jovanović son: «El cuento de Las orejas de Midas entre los sefardíes de Bosnia: contactos culturales», en Ladinar, 7-8 (2014), pp. 135-148; «Haim Davičo's Text Ženske Šale (Women's Jokes: A Sephardic Folktale or a Serbian Translation of Tirso de Molina's Los tres maridos burlados?», en Bulletin of Spanish Studies: Hispanic Studies and Researches on Spain, Portugal and Latin America, XCI (2014), pp. 1-22.

${ }^{26}$ Este trabajo es producto del Proyecto de investigación FF2012-31625 «Los sefardíes ante sí mis- 


\section{Cuentos medievales en la tradición sefardí}

\subsection{Espanto djustifikado}

Con este título encontramos una narración incluida en el libro de Matilda Koen-Sarano, Djoha ke dize? Kuentos populares djudeo-espanyoles ${ }^{27}$. El relato le fue contado en 1984 por Miriam Raymond, una mujer nacida en Milán, hablante de cuatro idiomas -judeoespañol, hebreo, inglés e italiano-y cuyos padres provenían de Turquía. El cuento dice así:

Djohá está en la ventana kon la mujer i afuera está pasando una levayá.

Al lado de la kasha está kaminando la mujer del muerto, vistida de preto, ke está yorando i kitandose los ojos, i está diziendo: «El prove de mi marido! Se está indo a un lugar onde no ay luz, no ay a komer... onde aze frío! Dinguno no va tener kudiado d'él, kuando va tener ambre, kuando va tener frío i kuando va estar al eskuro!».

Djohá, sintiendo estas palavras, se abolta a la mujer i le dize: «Presto! Serra la puerta! Esta djente se sta dirijendo a muestra kaza, para deshaldo akí! $\rangle^{28}$.

Como habrá podido deducir el lector, la anécdota aparece inserta en el Tratado III del Lazarillo de Tormes, cuando Lázaro se encuentra al servicio del escudero, en cuya casa -recordemos- no hay absolutamente nada:

Arriméme a la pared, por darles lugar, y, desque el cuerpo pasó, venían luego a par del lecho una que debía ser mujer del difunto, cargada de luto, y con ella otras muchas mujeres; la cual iba llorando a grandes voces y diciendo:

-Marido y señor mío, ¿adónde os me llevan? ¡A la casa triste y desdichada, a la casa lóbrega y obscura, a la casa donde nunca comen ni beben!

Yo que aquello oí, juntóseme el cielo con la tierra y dije:

«Oh desdichado de mí! Para mi casa llevan este muerto» ${ }^{29}$.

Alberto Blecua, en su edición de 1981 del Lazarillo, señalaba de dónde pudo tomar el anónimo autor de la obra esta facecia: «La anécdota se

mos y sus relaciones con España III. Hacia la recuperación de un patrimonio cultural en peligro» del Ministerio de Economía y Competitividad de España.

${ }^{27}$ Koen-Sarano, Djoha ke dice?..., p. 345. Copiamos el texto tal y como allí aparece recogido.

${ }^{28}$ Aclaramos algunos términos que, en nuestra opinión, pueden ofrecer alguna dificultad de comprensión al lector: levayá 'cortejo fúnebre, entierro'; kasha 'caja, ataúd'; preto 'negro, triste, penoso'; prove 'pobre'; indo 'yendo'; se abolta 'se vuelve'; djente 'gente'; kaza 'casa'. La expresión «kitandose los ojos» aparece recogida en Nehama como «être cause de ses propres déboires, de son propre malheur», Joseph Nehama, Dictionnaire du Judéo-Espagnol, Madrid, CSIC, 1977, s. v. kitár.

${ }^{29}$ Lazarillo de Tormes, ed. de Francisco Rico, Madrid, Cátedra, 1996, p. 96. 
encuentra ya en un cuento árabe del siglo x, y se halla también en el Liber facetiarum de Pinedo y en el Arte de Furtar de Antonio Vierra ${ }^{30}$. Unos años más tarde, en 1996, Francisco Rico, comentando este episodio añadía:

Se trata, en efecto, del calco de un chascarrillo de origen árabe que ya contaba al-Bayhaqui en el siglo x y aún repetía ibn 'Asim en la Granada nazarí de hacia 1400. El anónimo debió conocerlo por tradición oral y, gustando de su innegable gracia, no resistió la tentación de endosárselo a Lázaro $[\ldots]^{31}$.

Por lo tanto, como sucede en tantas ocasiones con la cuentística medieval, la historia proviene de la tradición árabe. Pudo pasar entonces a la tradición sefardí antes de que los judíos fueran expulsados de la Península. En España la anécdota ha sido bien conocida, de ahí que se recogiera en varias obras de los Siglo de Oro y de que, incluso hoy en día, existan zonas donde se conoce y se cuenta todavía como chiste ${ }^{32}$.

En el caso del Lazarillo sabemos, además, que la obra fue compuesta por su anónimo autor basándose en numerosas fuentes de la literatura anterior, ya que encontramos analogías con farsas medievales, cuentos franceses, el Asno de Oro de Apuleyo, el Amadís de Gaula, los relatos de Till Eulenspiegel, etc., además de chistes y chascarrillos tomados de la tradición oral y popular ${ }^{33}$. Con toda probabilidad, por tanto, la anécdota era bien conocida desde la Edad Media. Lo llamativo, además, es que tanto Lázaro como Djohá son personajes que comparten bastante características. El pícaro castellano se asemeja en muchas ocasiones a Djohá, personaje muy conocido en el cuento oriental desde la Alta Edad Media. Los primeros testimonios sobre él se encuentran en un libro iraquí del siglo x y ya era bastante popular en Persia en el siglo $\mathrm{XIII}^{34}$. Es un personaje complejo, que puede resultar sabio o tonto, pero tam-

${ }^{30}$ Lazarillo de Tormes, ed. de Alberto Blecua, Madrid, Castalia, 1981, p. 146, nota 255, donde amplía bibliografía sobre esta anécdota, así como en la edición de Francisco Rico - citada en nota anterior-, pp. 113 y 114 , notas $65-67$.

${ }^{31}$ Lazarillo... ed. de F. Rico, p. 114 de la introducción.

${ }^{32}$ Quiero dar las gracias a mi alumna Sara Rodríguez Ríos, quien me informó de que en casa de su abuela había un casete con chistes asturianos en el que aparecía este. Lo registra Jesús Suárez López en la página 191 de su obra Cuentos del Siglo de Oro en la tradición oral de Asturias (Red de Museos Etnográficos de Asturias, 2009, $2^{\text {a }}$ edición en soporte digital, disponible en la siguiente dirección en línea: http:/www.anincat.org/wp-content/uploads/2013/11/iso-8859-1Cuentos-del-Siglo-de-Oro-en-latradici\%C3\%B3n-oral-de-Asturias.pdf) [consultada el 22 de junio de 2015].

${ }^{33}$ Aunque siempre es necesario matizar, tal y como apuntó Francisco Rico: «Conviene extremar la cautela a la hora de repasar los materiales aprovechados en el Lazarillo. Ni es prudente tratarlos de folclóricos con la indiscriminación con que a menudo sigue haciéndose, ni menos cabe echar mano del folclore como panacea exegética», Lazarillo..., ed. de F. Rico, p. 83 de la introducción.

${ }^{34}$ Clara M. ${ }^{a}$ Thomas de Antonio, «Ŷuhāa, un personaje popular en el Magreb y en todo el mundo árabe», en Al-Andalus Magreb, 1 (1993), pp. 187-223. Datos tomados de la p. 189. 
bién pícaro. En ocasiones resulta fácil engañarle, pero, en otras, se muestra sagaz y astuto. Así lo describía Koen-Sarano:

El Djohá de los djudiós espanyoles, ke difundieron la figura en sus peregrinasiones en la konka del Mediterráneo, puede ser kriatura o viejo, kazado o soltero, riko o prove, onesto o malonesto, entelijente o bovo, i sovre todo naívo o embrolión. Es posible toparlo en todas las situasiones posibles [...]. Djohá, sigún mis enformantes, tiene tres aspektos fondamentales: puede ser bovo, savio o «diavlo» [...], i a las vezes todo esto endjuntos ${ }^{35}$.

Así pues, tanto Lázaro como Djohá son personajes que, en algunos momentos, pueden presentar semejanzas. Recuérdese, además, que una teoría bastante extendida entre los estudiosos de la primera novela picaresca española es si el anónimo autor del Lazarillo pudo ser un judío converso ${ }^{36}$. Los motivos para suponerlo son diversos y no nos detendremos ahora en analizarlos, pero sí quisiéramos destacar que esa posibilidad pudo hacer también que el pícaro castellano se asentara sobre esas fuentes medievales en las que el personaje de Djohá era bien conocido por musulmanes y judíos en la Península en la Edad Media.

\subsection{Un prokseso entresante}

Con este título apareció en el periódico sefardí Ilustra Güerta de Istoria el texto que ahora analizamos. Dicha publicación vio la luz entre los años 1880 y 1882 en la ciudad de Viena. Este periódico estaba dirigido por Shem Tov Semo, quien fue una de las figuras más destacadas dentro de la comunidad

${ }^{35}$ Tomado de la siguiente página web: http//ladinokomunita.tripod.com/articles/djoha.html [consultada el 5 de noviembre de 2014]. Aclaramos algunos términos: konka 'cuenca'; kriatura 'hijo, niño pequeño'; kazado 'casado'; prove 'pobre'; malonesto 'malvado, deshonesto'; entelijente 'inteligente'; naivo 'ingenuo, inocente'; embrolión 'enredador, intrigante, embrollador'; topar 'encontrar'; endjuntos 'juntos'.

${ }^{36} \mathrm{Se}$ han aducido diversas teorías para defender dicha tesis. El primero en hacerlo fue, obviamente, Américo Castro en su libro España en su historia. Cristianos, moros y judios, Buenos Aires, Losada, 1948. Más fundamentada fue la visión de Marcel Bataillon, especialmente a través de dos obras: Novedad y fecundidad del Lazarillo de Tormes, Salamanca, Anaya, 1968; y Pícaros y picaresca, Madrid, Taurus, 1969. En la actualidad, la mayor parte de la crítica considera que no existen pruebas contundentes para sustentar que el autor del Lazarillo fuese un judío converso. Véanse los trabajos de Pedro Martín Baños: «Nuevos asedios críticos al Lazarillo de Tormes. I», en Per Abbat. Boletín filológico de actualización académica y didáctica, 3 (2007), pp. 7-22; y, especialmente para este asunto, «Nuevos asedios críticos al Lazarillo de Tormes. II», en Per Abbat. Boletín filológico de actualización académica y didáctica, 4 (2007), pp. 7-32. Con todo, no debe olvidarse que de la pluma de algunos judíos conversos salieron algunas de nuestras novelas picarescas más conocidas como, por ejemplo, el Guzmán de Alfarache de Mateo Alemán. 
sefardí vienesa ${ }^{37}$. La prensa periódica sefardí había iniciado su andadura a mediados del siglo XIX, cuando los influjos de la cultura occidental comenzaron a penetrar en el tradicional mundo sefardíi ${ }^{38}$. Entre sus páginas encontramos contenidos de muy diversa naturaleza. Hubo periódicos de información general, de tendencias políticas diversas, y no fueron pocos los que se decantaron por temas festivos, humorísticos, pero también culturales y literarios, como es el caso del que nos ocupa ${ }^{39}$.

${ }^{37}$ Shem Tov Semo (1827-1881) fue un periodista, escritor y traductor de la segunda mitad del siglo XIX y uno de los pioneros del periodismo sefardí en Viena. Entre los trabajos que se han dedicado a su obra, véanse, fundamentalmente: David M. Bunis, «Shem Tov Semo, Yosef Kalwo and Judezmo Fiction in Nineteenth-Century Vienna», en Sefarad an der Donau. Lengua y literatura de los sefardies en tierras de los Habsburgo, ed. de Michael Studemund-Halévy, Christian Liebl e Ivana Vučina Simović, Barcelona, Tirocinio, 2013, pp. 39-106; Stephanie Von Schmädel, «Sem Tob Semo y la producción literaria sefardí de Viena en el siglo XIX», en La lengua sefardí. Aspectos lingüísticos, literarios y culturales, ed. de Yvette Bürki y Elena Romero, Berlín, Frank \& Timme, 2014, pp. 235-250. Pueden verse más datos en la página Sefardiweb del CSIC: http://www.proyectos.cchs.csic.es/sefardiweb/node/21 [consultada el 6 de noviembre de 2014].

${ }^{38}$ Véase en este mismo trabajo nota al pie 7.

${ }^{39}$ La mayor parte de estos periódicos -como este Ilustra Güerta de Istoria- se imprimieron en judeoespañol aljamiado, esto es, judeoespañol escrito con caracteres hebreos. No obstante, también existieron periódicos sefardíes escritos en caracteres latinos e incluso en otras lenguas -como el francés o el hebreo, por ejemplo-, dándose el caso de publicaciones en varios idiomas: el periódico Salonik (Salónica, 1869) llegó contener partes en «judeoespañol, búlgaro, turco y griego» en Iacob M. Hassán, «El estudio del periodismo sefardí», en Sefarad, 26 (1966), pp. 229-235, cita de la p. 231. Los estudios e investigaciones en torno a la prensa sefardí publicada entre mediados del siglo XIX y la segunda guerra mundial son cada vez más numerosos, aunque queda mucho por analizar, ya que son cientos los periódicos conservados. Entre los estudios más destacados, cabe citar: el catálogo, en hebreo, de Moshe David Gaon, A bibliography of the Judeo-Spanish (Ladino) press, Tel Aviv, Monoline Press, 1965; el artículo-reseña que dedicó a este libro Iabob M. Hassán, «El estudio del periodismo»...; Michael Molho, Literatura sefardita de Oriente, Madrid, CSIC, 1960, especialmente pp. 327-337 y 351-356; Elena Romero, La creación literaria en lengua sefardí, Madrid, MAPFRE, 1992, capítulo 5 dedicado al periodismo. Sobre el papel de la prensa en la sociedad sefardí: Sarah Abrevaya Stein, Making Jews Modern. The Yiddish and Ladino Press in the Russian and Ottoman Empires, Bloomington \& Indianapolis, Indiana University Press, 2004. Para la historia del periodismo en el Oriente Mediterráneo y en América, consúltense: Marc D. Angel, La América. The The Sephardic Experience in the United States, Filadelfia, Jewish Publication Society, 1982; Esther Benbassa, «Presse d'Istanbul et de Salonique au service du sionisme (1908-1914): Les motifs d'une allégeance», en Revue Historique, 276:2 (560) (1986), pp. 337-365; Mordehay Arbell, «El jurnalizmo sefaradi en Viena», en Aki Yerushalayim, 17 (54) (1996), pp. 24-25; Richard Ayoun, «La prensa djudeo-espanyola en Izmir antes de 1914», Aki Yerushalayim, 18 (56) (1997), pp. 40-42; y del mismo, «Des journaux Judéo-Espagnols à Izmir et à Salonique jusqu'à la veille de la première guerre mondiale», en Judeo Espaniol: The evolution of a culture, ed. de Rafael Gatenio, Salónica, Ets Ahaim Foundation, 1999, pp. 89-102; Aviva Ben-Ur, «In Search of the American Ladino Press: A Bibliographical Survey, 1910-1948», en Studies in Bibliography and Booklore, 21 (2001), pp. 10-52; Gad Nassi, ed., Jewish Journalism and Printing Houses in the Ottoman Empire and Modern Turkey, Estambul, Isis, 2001; Yitzchak Kerem, «The development of Judeo-Spanish press in Salonika 1864-1941. A vehicle for modernization and enhanced Sephardic identity», en Neue Romania, 28 (2003) (= Judenspanisch VII), pp. 155-167; Pablo Martín Asuero y Karen Gerson Şarhon, eds., Ayer y hoy de la prensa en judeoespañol, Estambul, Isis, 2007. Como ejemplo de la prensa como vehículo fundamental para el desarrollo de las comunidades sefardíes: Paloma Díaz-Mas y María Sánchez-Pérez, eds., Los sefardies ante los retos del mundo contem- 
Este relato apareció publicado dentro de una sección concreta del periódico denominada «Sala de pasatiempo»-que aparecía al final de prácticamente todos los números que conservamos- y donde se incluían cuentos, relatos festivos, chistes, adivinanzas, etc., es decir, fundamentalmente contenidos literarios, muchos de ellos pertenecientes a la cultura oral ${ }^{40}$. El texto dice así ${ }^{41}$ :

\section{Un prokseso entresante}

Tres kompradores de bois arivaron a_una en la sivdad Berlino por azer sus empleos i tomaron también en una kamareta en un hotel ${ }^{42}$ sus moradas.

Aí, en esta kamareta, se apalavraron dar a_guadrar sus monedas al patrón del hotel i ansí fue. Eyos ataron sus monedas en un paketo, lo yamaron al patrón del hotel, se lo entregaron en su poder i le disheron: «Dientro de este paketo se topa la suma de 45 mil taleres en papel. Esta suma trushimos mozotros tres akí por azer nuestros enpleos. Y siendo no keremos yevar la moneda kon nos por las plasas, se a damos aguadrar a usted kon la kondisión torna entregarmola a nozotros tres».

El patrón del hotel fue akavidado avrió el paketo i kontó torna la moneda i la topó djusta. Torna la seró i la guadró. Los tres forestos se fueron la manyana a la plasa kada uno a su echo, empero no pasaron 2 oras tornó el uno de los tres onde el patrón del hotel i le demandó la moneda i sin dudar muncho se la entregó el patrón del hotel.

Empero el día entero pasó i la otra noche los dos merkaderes tornaron al hotel i el tresero no fue más visto i a la fin se supo ke el tresero se fuyó kon la moneda de sus dos kolegas. Los merkaderes demandaron agora la moneda ke les page el patrón del hotel según la kondisión ke le izieron ke él no puede entregar la moneda si no están todos tres a uno.

poráneo. Identidad y mentalidades, Madrid, CSIC, 2010; Rosa Sánchez y Marie-Christine Bornes Varol, eds. (2013), La presse judéo-espagnole, support et vecteur de la modernité, Estambul, Libra, 2013.

${ }^{40}$ Un estudio sobre los acertijos y adivinanzas de este periódico puede verse en María SánchezPérez, «Acertijos y adivinanzas en el periódico sefardí Ilustra Güerta de Historia (Viena, 1880-1882)», en Sefarad, 73.1 (2013), pp. 225-254.

${ }^{41}$ Dado que este texto que ofrecemos al lector es una transcripción de un original aljamiado, señalamos a continuación el sistema de transcripción utilizado y las equivalencias gráfico-fonéticas: $b$ bilabial oclusiva sonora $/ \mathrm{b} / ; v$ bilabial fricativa sonora $/ \mathrm{b} / ; d j$ prepalatal africada sonora $/ \hat{\mathrm{y}} / ; h$ uvular fricativa sorda $/ Y / ; j$ prepalatal fricativa sonora $/ \check{z} / ; l y$ lateral palatal $/ \lambda /$, que la mayor parte de las veces se realiza en judeoespañol como $/ \mathrm{y} / ; n y$ nasal palatal $/ \mathrm{g} / ; s$ alveolar fricativa sorda $/ \mathrm{s} / ; z$ alveolar fricativa sonora $/ \mathrm{z} / ; s h$ prepalatal fricativa sorda / $/ \mathbf{s} / ; t s$ alveolar africada sorda $/ \hat{\mathrm{s}} /$. Puntuamos y acentuamos el texto. El texto procede de microfilmes de la Biblioteca Nacional de Israel y de fotografías digitales de periódicos sefardíes, tomadas directamente a partir de los originales que se hallan en la biblioteca del Instituto Ben Zvi (Jerusalén).

${ }^{42}$ En todos los casos, la palabra «hotel» aparece así: הוטיל. El hecho de que el término se inicie con la letra hebrea «he» indica que existe una influencia clara de lenguas como el francés o el castellano, por ejemplo, ya que la palabra en caracteres latinos se escribe con «h» inicial. Si a ello unimos que, en el texto aparezca «bois», tal y como se escribe (no como se pronuncia) en francés, y «forestos», relacionado con «fôret», parece indicar que el cuento fue tomado de una fuente escrita, probablemente francesa. 


\section{María SÁNCHEZ-PÉREZ}

El prokseso vino delantre del tribunal de Berlino i lo ovligó al patrón del hotel ke depozitee la moneda en el tribunal diziéndole al patrón del hotel: los enteresos de este importo gozaresh vos asta ke no traen estos dos senyores al tresero ke estuvo kon eyos, kuando vos entregaron la moneda según la kondisión ke vos izieron a vos al entregarvos la moneda, deve el alto tribunal también sostenerla ${ }^{43}$.

Se trata de un relato de amplia difusión, incluido en los índices de Thompson, que se correspondería con el Tipo 1591 «Los tres depositarios asociados» y el Motivo J161.1 «Los tres depositarios recobrarán el dinero cuando se reúnan ${ }^{44}$. Como es lógico, existen diferentes versiones del cuento. En algunas de ellas, en lugar de un juez, es un niño o una vieja el personaje que resuelve el engaño. En el estudio Cuento y novela corta en España de María Jesús Lacarra analiza la versión incluida en el Sendebar, con el título «El niño de cinco años» y allí señalaba:

La anécdota remite al mundo de los litigios originados por los tesoros mal guardados o los depositarios infieles, tema ampliamente representado en la literatura oriental -Mil y una noches; Disciplina Clericalis, XV, XVI y XVII, etc. $-\mathrm{y}$ en algunos fueros. El interés de estos relatos estriba en la habilidad del juez o personaje auxiliar -muchas veces una vieja o un niño, siempre edades extremas, o un sabio, como Demóstenes- para resolver un engaño. Valerio Máximo narra en sus Hechos y dichos memorables, VIII, 3, un cuento similar, protagonizado por Demóstenes [...], de donde pasaría, entre otros, al Alphabetum narrationum, núm. 139, y su versión catalana, el Recull de exemplis, núm. 118; a la Scala Coeli de Jean Gobi, núm. 47; al Speculum historiale de Vicente de Beauvais, III, capítulo 91; al Schimpf und Ernst de Johannes Pauli, núm. 113; a la Glosa castellana al Regimiento de príncipes, libro III, capítulo 21; a Walter de Burley, La vida y las costumbres de los viejos filósofos, capítulo 37, al Libro de los exemplos por a.b.c., núm. 78 o a los Jestbooks, 2, 330-333 de Shakespeare ${ }^{45}$.

\footnotetext{
${ }^{43} \mathrm{El}$ texto se encuentra recogido en el volumen I, periódico número 2, p. 48, cols. a y b. Aclaramos algunos términos: prokseso 'proceso (judicial)'; entresante 'interesante'; bois 'madera'; a_una 'al mismo tiempo, a la vez'; sivdad 'ciudad'; Berlino 'Berlín'; kamareta 'habitación'; ai 'ahí'; guadrar 'guardar'; paketo 'paquete'; dientro 'dentro'; topa 'encuentra'; taleres 'antigua moneda de plata alemana'; mozotros 'nosotros'; akavidado 'advertido, precavido'; torna 'vuelve a, de nuevo, otra vez'; guadró 'guardó'; forestos probablemente, proviene del francés fôret 'bosque' para referirse a estos trabajadores de la madera'; onde 'donde'; tresero 'tercero'; fuyó 'huyó'; agora 'ahora'; enteresos 'intereses'; senyores 'señores'; eyos 'ellos'.

${ }^{44}$ Apud. ed. de María Jesús Lacarra, Cuento y novela..., p. 88.

${ }^{45} \mathrm{Ibidem}$, p. 89. El estudio y el cuento completo se encuentran entre las pp. 88-92.
} 
Vemos, por tanto, cómo la anécdota tuvo amplia difusión por varios países y culturas, por lo que no sorprende que también se haya conservado en la cultura sefardí.

\subsection{Todo es relativo}

Así titula Matilda Koen-Sarano este cuento de la tradición sefardí recogido por ella en 1990 y cuya informante fue Ester Levy, nacida en Jerusalén en 1920 y hablante de cinco idiomas -judeoespañol, hebreo, árabe, francés e inglés-46.

Avía un hombre muy muy prove. Kada vez ke vinía a kaza era la mujer gritos... piliar... «Addió! No stas lavorando! No stas ganando! No stas traendo nada a kaza!... Kualo va ser?».

El ombre ya se va murir. Al kavo un día disho: «Yalla, Yo me v'a fuyir de kaza? Me v'a matar... No kero mas saver!».

Al kamino se merkó medio kilo de ful. S'asintió en una muntanyika. Stava yorando... yorando i kumiendo... yorando i kumiendo... Disho: «Skapó! Me vo matar! No kero mas nada!».

En komiendo las avas, stava echando las kashkas abasho. Skapó de kumer, i kuando ya se stava echando abasho para matarse, vino un ombre viejo, le disho:

«addió! Mersí muncho por las kashkitas ke m’ichates! Na, kumí i me artí. No tinía kualo kumer kuantos días!».

Vido el ombre i disho: «Ay, ay, ay! Mira, ay mas negro en la vida. Yo no me vo matar» ${ }^{47}$.

Como - probablemente- ya habrá deducido el lector, se trata de una versión del conocido «Exemplo X» de El Conde Lucanor de don Juan Manuel: «De lo que contesçió a un omne que por pobreza et mengua de otra vianda comía atramuzes» ${ }^{48}$. En la edición de esta obra realizada por Guillermo Serés leemos lo siguiente:

\footnotetext{
${ }^{46}$ Copiamos exactamente de la versión recogida en Koen-Sarano, De Saragosa..., p. 148. Más datos de Ester Levy en p. 202.

${ }^{47}$ Aclaramos algunos términos: prove 'pobre'; piliar 'pelear'; yalla 'adelante' (es un tipo de exclamación, Koen-Sarano anota 'ensitasión'); merkó ‘compró'; ful 'habas' (Koen-Sarano lo explica como 'avas freskas'); skapó 'acabó, terminó'; kashkas ‘cáscaras'; mersi 'gracias’; kashkitas 'cascaritas'; negro 'malo'.

${ }^{48}$ Citamos de la siguiente edición: Don Juan Manuel, El Conde Lucanor, ed. de José Manuel Blecua, Madrid, Castalia, 1992, p. 92.
} 


\section{María SÁNCHEZ-PÉREZ}

Indirectamente, la anécdota procede de una máxima de Diógenes Laercio repetida en los Loci communes de San Máximo, en la Disciplina clericalis de Pedro Alfonso, de donde pudo sacarla don Juan, e incluso en la Summa de Santo Tomás de Aquino. También se ha apuntado que la fuente inmediata es un episodio de una obra perdida de Ibn Baskuwal que se conserva en la antología de Ibn $\mathrm{Sa}^{\prime} \mathrm{id}^{49}$.

El primero en mostrar estos antecedentes fue Francisco de la Granja, quien, en 1959, señaló la versión más probable de la que parece derivar esta anécdota ${ }^{50}$ :

Leyendo para otros fines la reciente edición del Mugrib de Ibn Sa'īd, he tenido la sorpresa de encontrar algo que es sin duda el origen de este apólogo de El Conde Lucanor. Se trata de un episodio autobiográfico de 'Abd al-Raḥmān al Qanāzi ${ }^{\prime} \overline{1}$, inserto en una obra perdida de Ibn Baškuwāl y recogido por Ibn $\mathrm{Sa}$ ‘̄d en su famosa antología ${ }^{51}$.

\section{Y más adelante recoge el relato de 'Abd al-Raḥmān al·Qanāzi‘ī:}

Estando en Egipto, presencié la fiesta con las gentes, que se marcharon a comer lo que tenían preparado, mientras yo me dirigía al Nilo. No tenía otra cosa para romper el ayuno que unos pocos altramuces que me habían sobrado, en un pañuelo. Descendí a la orilla y me puse a comerlos y a arrojar las cáscaras a mis pies, diciendo para mis adentros: ¿habrá hoy en Egipto, en esta festividad, alguien en peor situación que yo? Pero apenas levanté la cabeza vi ante mí un hombre que recogía y comía las cáscaras de los altramuces que yo tiraba. Comprendí que aquello era un aviso de Dios -honrado y ensalzado sea- y le di gracias ${ }^{52}$.

Indudablemente las versiones son muy similares, aunque en la actualidad no sabemos la fuente exacta de la que pudo extraerla don Juan Manuel, pues

\footnotetext{
${ }^{49}$ Don Juan Manuel, El Conde Lucanor, ed. de Guillermo Serés, estudio preliminar de Germán Orduna, Barcelona, Círculo de Lectores y Galaxia Gutenberg, 2006, p. 50. En esta edición se apunta (p. 354) que se trataría del motivo tradicional J.833.I.

${ }^{50}$ Se basa en dos de los primeros investigadores en dar la pista sobre este apólogo: Hermann Knust y Victor Chauvin. El primero con la siguiente edición: Don Juan Manuel, El Libro de los enxiemplos del conde Lucanor et Patronio, Leipzig, Herausgegeben von Adolf Birch-Hirschfeld, Dr. Seele Co., 1900. Y el segundo con la obra: Bibliographie des ouvrages arabes ou relatifs aux arabes publiés dans l'Europe Chrétienne de 1810 à 1885, Lieja, H. Vaillant-Carmanne, 1892-1922, 12 vols.

${ }^{51}$ Francisco de la Granja, «Origen árabe de un famoso cuento español», en Al-Andalus, 24 (1959), pp. 319-332; citamos de la p. 322.

${ }^{52}$ Ibídem, p. 326. Se recoge también este texto en la siguiente edición: Don Juan Manuel, El Conde Lucanor, ed. de Alfonso I. Sotelo, Madrid, Cátedra, 1999, p. 115, nota 1.
} 
una de las características que introdujo en El Conde Lucanor fue eliminar la referencia de donde tomaba los textos, intentando presentar así su obra como enteramente original, aunque en realidad no lo fuera y alejándose también del procedimiento escolástico de referir la auctoritas ${ }^{53}$. Además, el didactismo que encontramos en esta obra interesó especialmente a muchos autores del siglo XVII, de ahí que no resulte extraño que la misma anécdota fuese recogida más brevemente -aunque la esencia es la misma- por Pedro Calderón de la Barca en La vida es sueño:

Cuentan de un sabio, que un día
tan pobre y mísero estaba,
que sólo se sustentaba
de unas yerbas que cogía.
¿Habrá otro, entre sí decía,
más pobre y triste que yo?
Y cuando el rostro volvió,
halló la respuesta, viendo
que iba otro sabio cogiendo
las hojas que él arrojó ${ }^{54}$.

Se trata de una conocidísima décima de nuestras letras hispánicas. Tanto es así que, durante años, se utilizó como ejercicio escolar de memorización para aprender la métrica de dicha estrofa ${ }^{55}$. La diferencia más notable de esta última versión es que Calderón opta por hierbas y elimina los altramuces -palabra quizá poco poética-, mientras que en el resto de versiones se hace referencia claramente a ellos, tanto en El Conde Lucanor, como en el texto árabe, así como en el sefardí donde se mencionan las «habas frescas».

\section{Conclusiones}

Hemos visto únicamente tres ejemplos, pero resulta evidente que cuentos bien conocidos en la Edad Media han pervivido en la cultura sefardí hasta la actualidad. Verdad es que no podemos confirmar plenamente si dichos

\footnotetext{
${ }^{53}$ Lina Rodríguez Cacho, Manual de Historia de la Literatura Española, Madrid, Castalia, 2009, vol. I, pp. 81-85.

${ }^{54}$ Pedro Calderón de la Barca, La vida es sueño, ed. de Ciriaco Morón, Madrid, Cátedra, 1994, pp. 95-96. Se encuentra en la Escena II de la Primera Jornada, vv. 253-262. Aunque, en la actualidad, prácticamente toda la crítica admite que el texto de La vida es sueño deriva de El Conde Lucanor, Francisco de la Granja opina que Calderón pudo basarse directamente en el texto de 'Abd al-Raḥmān al·Qanāzi‘'i, idem, pp. 330-332.

${ }^{55}$ Así la aprendió mi madre en su niñez y así me la enseñó a mí cuando yo tenía doce o trece años, copiándomela entre las solapas de una carpeta escolar que utilicé durante varios cursos académicos.
} 
apólogos y facecias los conocieron cuando aún residían en la península Ibérica y, por tanto, formaron parte de su bagaje cultural antes de la diáspora, o bien si influyó su convivencia con otras culturas tras su expulsión de los territorios hispánicos y esas historias les llegaron por otra vía, oriental fundamentalmente. Es probable que nunca lleguemos a averiguarlo, pero lo destacado e importante es que anécdotas similares, versiones de una misma historia, etc., gustaron tanto a los habitantes de la Península en la Edad Media como a los sefardíes en la actualidad. Y no solo fueron objeto de deleite entonces, sino que los estudiosos de la Literatura vuelven sus ojos a esos textos que, en nuestro caso, se recogieron por escrito pronto, pero que en el caso de la cultura sefardí no ha sido así hasta épocas muy recientes.

Vayamos entonces un poco más allá: mientras que el cuento medieval hispánico se ha adscrito a esa literatura «culta o canónica»-al haber sido consignado por escrito-, los cuentos o las konsejas sefardíes se han visto relegadas a pertenecer a esa «otra» literatura, la popular, la marginada, en muchas ocasiones. Es cierto que, hasta hace relativamente poco tiempo, no contábamos con estudios ni antologías de cuentos sefardíes, pero cada vez existen más trabajos e investigaciones y hora es ya, parece, de elevar-o de ir elevando- a otra categoría toda esta producción literaria.

Por otro lado, todos estos cuentos nos permiten, a unos y otros, (re)conocernos como parte integrante de un conjunto, de una sociedad, de un todo. Porque, como afirmaba Matilda Koen-Sarano:

estos cuentos fueron y vienen todavía contados años y años después en la dulce lengua que nuestros padres conservaron con amor y fidelidad a través de los siglos, a pesar de la vicisitudes que los llevaron fuera de su amada «Sefarad»: el judeo-español [...] De hecho estos cuentos nos atan directamente a nuestros padres porque los recibimos de ellos en la manera más directa posible, quiero decir cara a cara y oralmente. Esto hizo nacer en nosotros una atadura que viene y queda más allá del tiempo, porque si bien ellos no están ya más con nosotros continúan viviendo en nuestro recuerdo por medio de los cuentos que nos narraban. Dos cosas fundamentales recibimos de ellos con estos cuentos: a través de estos nuestros padres y nuestras madres (y frecuentemente nuestros abuelos) nos educaron en las buenas maneras y las buenas obras, dándonos ejemplos que van a quedar impresos en nosotros durante toda la vida (porque un cuento es mucho más eficaz que cualquier prédica moral) y nos enseñaron a reír ${ }^{56}$.

${ }^{56}$ Matilda Koen-Sarano, De Saragosa..., art. cit., pp. 19-20. 
Durante generaciones estos cuentos se transmitieron de forma oral, cumpliendo con el precepto horaciano de delectare et prodesse. Así sucedió en las comunidades sefardíes durante siglos, pero no es menos cierto que estas historias también se escucharon contar en la Península durante centurias. Y las enseñanzas y los valores que todos estos cuentos encierran han servido para instruir deleitando desde la antigüedad hasta nuestros días. ¿Quiénes no hemos escuchado desde la niñez a nuestros mayores contarnos historias y cuentos de este tipo? Ya he señalado anteriormente cómo me llegó a mí, por primera vez, la historia del sabio que comía altramuces, pero ¿quién no ha escuchado alguna vez el famoso cuento de «La lechera ${ }^{57}$ ? Porque existen numerosas versiones de este apólogo y cualquiera de ellas sigue resultando ejemplar para instruir y enseñar. Y no solo se conoce en España, sino también en Portugal o en Cuba, por ejemplo, pero también en la tradición sefardís ${ }^{58}$.

A través de estas líneas hemos visto cómo algunos cuentos medievales han pervivido en la tradición oral sefardí contemporánea. Por un lado, uno de los textos apareció en un periódico judeoespañol publicado en Viena entre 1880 y 1882, es decir, que algunos de esos apólogos se transmitieron por medios escritos e incluso por un medio moderno, como es la prensa periódica, en cuyas páginas - la mayoría aljamiadas- se insertaron, a la altura de finales del siglo XIX y las primeras décadas del Xx, cuentos populares de origen medieval. Por otra parte, dos de los textos que hemos estudiado fueron recogidos por Matilda Koen-Sarano mediante encuestas orales en las últimas décadas del siglo xx.

Como señaló Carmen Hernández Valcárcel, haciéndose eco de unas palabras que pronunció Augusto Monrerroso en su discurso de recogida del Premio Príncipe de Asturias: «generación va y generación viene: mas el cuento siempre permanece ${ }^{59}$. Así pues, durante generaciones los cuentos se han transmitido oralmente o por escrito desde la más remota antigüedad hasta nuestros días. Nuestros antepasados se deleitaron con su lectura -silenciosa o en voz alta- $y$, al mismo tiempo, disfrutaron contando esas historias a

\footnotetext{
${ }^{57}$ La historia procede del Panchatantra y de ahí paso al Calila e Dimna. Posteriormente se popularizó gracias a don Juan Manuel, quien lo incluyó en El Conde Lucanor (ejemplo VII), Samaniego, Gil Vicente, etc.

${ }^{58}$ Como sabemos, la moraleja que encierra el cuento es que nadie debe hacerse ilusiones o castillos en el aire, nombre, precisamente, con el que aparece recogido en Matilda Koen-Sarano, Djoha ke dize?..., p. 69: «Kastiyos en ayre».

${ }^{59}$ Así comienza Carmen García Valcárcel su libro El cuento español en los Siglos de Oro, Murcia, Universidad de Murcia, 2002, vol. I, p. 25. El discurso de Augusto Monterroso puede leerse en la siguiente dirección web: http://www.fpa.es/es/premios-principe-de-asturias/premiados-2015/2000augusto-monterroso.html?texto $=$ discurso\&especifica $=0$ [consultada el 14 de enero de 2015]. Monterroso parafrasea el texto del Eclesiastés 1: 4: «Generación va, generación viene: mas la Tierra siempre permanece».
} 
sus amigos y a sus parientes. Porque, como hemos visto, muchos de ellos se aprendieron, se valoraron y transmitieron por sus ejemplares enseñanzas, pero es cierto también que otros servían simplemente para entretener, pasar el rato y hacer reír. En definitiva, para estrechar vínculos y lazos afectivos con nuestros mayores, con nuestra sociedad y nuestra cultura. Esa cultura que todavía nos une a tantos entre Oriente y Occidente.

Recibido: 20/03/2015

Aceptado: 14/06/2015

\section{$\cos$}

Pervivencias del CUENTO MEDIEVAl EN LA TRAdición SEFARdí CONTEMPORÁNEA

RESUMEN: El objetivo de este artículo es poner de manifiesto cómo diferentes cuentos medievales de la tradición hispánica han pervivido en la cultura sefardí contemporánea. Para ello, hemos estructurado el trabajo en varias partes: una introducción, una comparación entre el cuento medieval y la konseja sefardí, un breve estado de la cuestión y, posteriormente, un análisis comparativo de tres casos concretos.

Palabras Clave: Cuento medieval. Literatura española. Literatura sefardí. Konseja. Judeoespañol.

\section{SuRvivals of MEdieVAl tale In CONTEMPORARy SePHARDiC TRAdition}

ABstract: The aim of this article is to highlight how different medieval tales of the Hispanic tradition have survived in contemporary Sephardic culture. For it, this paper is divided in several parts: an introduction, a comparison between the medieval tale and the Sephardic konseja, a brief status of the issue and, subsequently, a comparative analysis of three specific cases.

Keywords: Medieval tale. Spanish literature. Sephardic literature. Konseja, JudeoSpanish. 